\title{
Detection and genotyping of Helicobacter pylori in saliva versus stool samples from asymptomatic individuals in Northeastern Thailand reveals intra-host tissue-specific $H$. pylori subtypes
}

\author{
Phattharaphon Wongphutorn ${ }^{1,2}$, Chariya Chomvarin ${ }^{1,2^{*}}$, Banchob Sripa ${ }^{3}$, Wises Namwat ${ }^{1,4}$ and Kiatichai Faksri ${ }^{1,4^{*}}$ (D)
}

\begin{abstract}
Background: Two-thirds of the world's population is thought to be infected by Helicobacter pylori. Although most people infected with H. pylori are asymptomatic, this pathogen is associated with several gastric pathologies including cancer. The risk factors for colonization are still unclear and the genetic diversity within individual hosts has never been clearly investigated.

Result: This study determined the prevalence of, and explored risk factors for, $H$. pylori infection directly from paired saliva $(n=110)$ and stool $(n=110)$ samples from asymptomatic persons in Northeast Thailand. Samples were subjected to indirect immunofluorescence assay (IFA), 16S rRNA-based real-time PCR and vacA-based semi-nested PCR. Partial vacA gene sequences of $H$. pylori were compared between saliva and stool samples.

The overall prevalence of $\mathrm{H}$. pylori infection in our asymptomatic study population was $64 \%$. Age, gender, occupation and frequency of brushing teeth were not found to be associated with H. pylori colonization. The vacA gene was successfully sequenced from both saliva and stool samples of 12 individuals. For seven of these individuals, saliva and stool sequences fell into different clusters on a phylogenetic tree, indicating intra-host genetic variation of $\mathrm{H}$. pylori.

Conclusion: This study reports a high prevalence of $\mathrm{H}$. pylori infection in asymptomatic persons in this region of Thailand and demonstrates that genotypes (vacA gene sequences) of H. pylori may differ between the oral cavity and intestinal tract.
\end{abstract}

Keywords: Helicobacter pylori, Genetic diversity, Genotyping, Saliva, Stool, vacA

\section{Background}

Helicobacter pylori infection is responsible for several gastric diseases, especially major ulcers in the stomach and small intestine. Transmission mechanisms of $H$. pylori are still unclear but the fecal-oral route might be the most important [1]. Approximately two-thirds of the world's population is infected by $H$. pylori, with the highest prevalences (up to 80\%) in developing countries [2]. In contrast, prevalences are tending to decline in

\footnotetext{
* Correspondence: chariya@kku.ac.th; kiatichai@kku.ac.th

${ }^{1}$ Department of Microbiology, Faculty of Medicine, Khon Kaen University, Khon Kaen 40002, Thailand

Full list of author information is available at the end of the article
}

industrialized countries but are typically in the region of $40 \%[1,3]$. Although $H$. pylori infection remains asymptomatic in most people, its presence is associated with an increased risk of various gastric pathologies, especially gastric cancer [4]. Moreover, this pathogen might be involved in the pathogenesis of some liver diseases such as gall stone, chronic cholecystitis and cholangiocarcinoma [5-9].

The isolation of $H$. pylori is difficult due to the fastidious nature of the organism. This affects estimates of prevalence: different methods and different types of sample can yield different results [10-12]. Previous estimates of the prevalence of $H$. pylori infection in stool samples of asymptomatic 
persons have ranged from $6.8 \%$ to $73.3 \%$ [10-14]. Corresponding values for saliva samples are $45.7 \%-67.8 \%$ $[10,11,15]$. In Thailand, only one study has so far investigated the prevalence of $H$. pylori infection in stool samples of asymptomatic persons [13]. No study has combined several methods of detection to compare the prevalences and genotypes of $H$. pylori infection from paired stool and saliva samples. Although socioeconomic status, especially hygienic conditions during childhood, was suggested to be associated with $H$. pylori infection [1], risk factors for colonization are still unclear.

Each Helicobacter species has a preferred niche within the body, facilitating their classification into gastric (localize in gastric mucosal surface) and enterohepatic (localize in ileum, colon and biliary tree) species [1]. H. pylori is a gastric species. A few studies have investigated the genetic variation of $H$. pylori among tissue sites based on presence/ absence of genetic structure, but used methods with low discriminatory power relative to gene sequence analysis $[16,17]$. One study has compared ure $C$ sequences of $H$. pylori between saliva samples and gastric biopsies from three patients, but no clear difference was found [18]. There have been no previous studies to investigate intrahost genetic diversity based on gene sequences among different tissues in asymptomatic individuals.

This study aimed to 1) determine the prevalence of $H$. pylori infection in asymptomatic persons in Northeast Thailand using a combination of molecular and immunological methods; 2) investigate the association between the H. pylori colonization and demographic-socioeconomic status of the host, and 3) investigate the intra-host genetic diversity of $H$. pylori by comparing strains isolated from saliva and stool samples.

\section{Methods}

\section{Setting and populations}

One-hundred and ten healthy persons (44 males and 66 females) living in Mancha Khiri district $(n=80)$, Khok Pho Chai District $(n=10)$ in Khon Kaen Province and Kamalasai District in Kalasin Province $(n=20)$ of Thailand were recruited into the study during the period March 2014 to December 2015. The participants (i) were between 18 and 60 years of age, (ii) had no previous diagnosis of gastric carcinoma, gastritis, dyspepsia or other gastrohepatobiliary diseases, (iii) had no history of severe alcohol abuse, (iv) reported no usage of proton pump inhibitor (PPI), bismuth-containing compounds or antibiotics within 4 weeks prior to recruitment.

\section{Data and specimen collection}

Demographic data were collected by questionnaire used previously [19]. Saliva collection was performed according to [20] with slight modification by including post-collection enrichment on Brucella broth. Approximately $3 \mathrm{ml}$ of saliva and $2 \mathrm{~g}$ of stool samples were collected from each participant and stored at $-80 \quad$ C. Written ethical consents were received from participants. The study was approved by Institutional Human Ethics Committee of Khon Kaen University (HE571489).

\section{DNA extraction}

DNA was extracted from $1 \mathrm{ml}$ of saliva and $1 \mathrm{~g}$ of stool samples using the Puregene DNA Purification System (Gentra System, USA) and QIAamp ${ }^{\circ}$ Fast DNA Stool Mini Kit (Qiagen, USA), respectively, according to manufacturers' instructions.

\section{Semi-nested PCR for detection of $\boldsymbol{H}$. pylori}

$v a c \mathrm{~A}$ of $H$. pylori was amplified by semi-nested PCR using specific primers, vac F1/F2 and R1 followed by vac F1/F2 and R2 (Table 1). PCR was performed in a total volume of $25 \mu \mathrm{l}$ containing $500 \mathrm{ng}$ DNA template, 1X PCR buffer (+ $1.5 \mathrm{mM} \mathrm{MgCl} 2), 0.4 \mu \mathrm{M}$ of each primer, 0.5 unit of Taq DNA polymerase (RBC bioscience, Taipei, Taiwan) and $0.2 \mathrm{mM}$ dNTP (Amresco, Ohio, USA) using a thermal cycler $\left(\mathrm{C}_{1000}{ }^{\text {tu }}\right.$ Thermal Cycler, BioRad). PCR conditions and primer sequences are shown in Table 1. Amplified products were separated by electrophoresis in a $1.5 \%$ agarose gel and visualized by staining with ethidium bromide.

\section{SYBR-green real-time PCR for detection of $H$. pylori}

A portion of the 16S rRNA of H. pylori was amplified using a PCR mixture containing $2 \mathrm{X}$ of SsoAdvanced ${ }^{\mathrm{Tm}}$ universal SYBR $^{\circ}$ Green supermix (BioRad, Canada), $1 \mu \mathrm{M}$ of each specific primer and 100-500 ng of DNA template. Distilled water was added to produce a final volume of $10 \mu \mathrm{l}$ and the reaction was run in a CFX96 ${ }^{\mathrm{ma}}$ Real-Time System. The results were analyzed using CFX Manager Version 3.1 (BioRad, USA). The PCR conditions and primer sequences are shown in Table 1.

\section{Indirect immunofluorescence assay (IFA) for detection of H. pylori}

IFA was performed according to the protocol previously described [21]. For saliva, $1 \mathrm{ml}$ of each sample was centrifuged at 13,000 rpm for $10 \mathrm{~min}$ and supernatant was discarded and then $1 \mathrm{ml}$ of Brucella broth (CRITERION, USA) was added to the pellet and incubated for 3 days. One $\mathrm{ml}$ of suspension was then centrifuged at 13,000 rpm for $5 \mathrm{~min}$ and the pellet was washed 3 times using PBS. Then, $30 \mu \mathrm{l}$ of cell suspension was dropped onto a slide and allowed to dry. Then, $30 \mu \mathrm{l}$ of primary mouse anti- $H$. pylori IgG (Santa Cruz Biotechnology, USA) was added onto the slide and incubated at $4{ }^{\circ} \mathrm{C}$ for at least $1 \mathrm{~h}$. The slide was washed 3 times using PBS, dried and then $30 \mu \mathrm{l}$ of secondary goat anti-mouse IgG-conjugated fluorescein isothiocyanate (FITC) (Dako ${ }^{\circ}$, Denmark) was added and incubated for $1 \mathrm{~h}$. The slide was washed using PBS and 
Table 1 Primer sequences and PCR conditions for molecular detection of H. pylori

\begin{tabular}{|c|c|c|c|c|}
\hline Genes & Primer names: sequences $\left(5^{\prime}>3^{\prime}\right)$ & Product size (bp) & PCR conditions & Ref. \\
\hline \multirow[t]{4}{*}{ vacA } & F1/2: GCATGATTTTGGCACCATTG & 429 & $95^{\circ} \mathrm{C} 30 \mathrm{~s}, 52^{\circ} \mathrm{C} 30 \mathrm{~s}$ & [21] \\
\hline & R1: TTाTCATATTTAGGGGCAAA & & $72^{\circ} \mathrm{C} 45$ s (35 cycles) & \\
\hline & F1/2: GCATGATTTTGGCACCATTG & 276 & $95^{\circ} \mathrm{C} 30 \mathrm{~s}, 62^{\circ} \mathrm{C} 30 \mathrm{~s}$, & \\
\hline & R2: ATCGCATTGCTCAAGCTCAA & & $72^{\circ} \mathrm{C} 45$ s (35 cycles) & \\
\hline \multirow[t]{2}{*}{$16 \mathrm{~S}$ rRNA } & F: CTCATTGCGAAGGCGACCT & 139 & $95^{\circ} \mathrm{C} 20 \mathrm{~s}, 58^{\circ} \mathrm{C} 30 \mathrm{~s}$, & [43] \\
\hline & R: TCTAATCCTGTTTGCTCCCCA & & $72^{\circ} \mathrm{C} 45$ s (35 cycles) & \\
\hline
\end{tabular}

dried. Then, $5 \mu \mathrm{l}$ of mounting solution (PBS and glycerol; 50:50) was added and closed by cover slip. Finally, sample slides were observed for the presence of fluorescent bacteria under a fluorescence microscope (Nikon, Japan).

For stool, $1 \mathrm{ml}$ of Brucella broth was added to $1 \mathrm{~g}$ of stool sample and homogenized. The suspension was then centrifuged at 13,000 rpm for $1 \mathrm{~min}$. Supernatant was separated and then $500 \mu \mathrm{l}$ of Brucella broth was added to the supernatant and incubated for 3 days. One $\mathrm{ml}$ of suspension was centrifuged at 13,000 rpm for $5 \mathrm{~min}$ and pellet was washed 3 times using PBS. Then, $30 \mu \mathrm{l}$ of cell suspension was dropped onto a slide, dried and further tested as described above.

\section{Limits of detection (LODs) of $H$. pylori using molecular methods and the immunological method}

Methods for determining LODs in spiked-stool samples were modified from [22]. To prepare spiked-stool samples, bacterial suspension of $H$. pylori was added to produce stool containing from $10^{0}$ to $10^{8}$ cells $/ \mathrm{ml}$. The crude DNA sample from each dilution was extracted from $1 \mathrm{ml}$ of stool suspension using a commercial DNA extraction kit (QIAamp ${ }^{\circ}$ Fast DNA Stool Mini Kit; Qiagen, USA) and was used to determine the LODs of semi-nested PCR and real-time PCR. One $\mathrm{ml}$ of bacterial suspension from each dilution was inoculated into $0.1 \mathrm{~g}$ of stool samples and was used to determine the LOD of IFA.

\section{vacA sequencing and phylogenetic analysis}

Amplified products of vacA (276 bp) of $H$. pylori from all vacA-positive samples based on semi-nested PCR were sequenced by a DNA sequencing service (BIONEER, Korea) in both forward and reverse strands.

Phylogenetic analysis of $H$. pylori strains based on vacA was performed based on the maximum likelihood (ML) method in MEGA-7 [23] using the Kimura 2-parameter model of nucleotide substitution and a gamma model of rate heterogeneity (the model giving the best loglikelihood value). The phylogenetic tree was constructed based on 1000 bootstrap replicates.

\section{Data analysis}

Criteria for a true positive result of $H$. pylori detection were modified from [24]: at least two of the following three methods must be positive for a given sample; IFA, semi-nested PCR and SYBR-green real-time PCR. Descriptive statistics were used to describe overall results. Pearson's chi-squared test was used to analyze the relationship between socioeconomic status, oral hygiene and the presence of $H$. pylori in saliva and stool samples. Odds ratios (ORs) and 95\% confidence intervals (CIs) were calculated. Multivariate logistic regression analysis was used to evaluate relationships of risk factors to $H$. pylori infection by adjusting for age, and gender. SPSS version 16 (SPSS Inc., Illinois, USA) was used. A p-value $<0.05$ was considered to be statistically significant.

\section{Results}

Prevalence and detection of $H$. pylori in 110 healthy, asymptomatic persons in northeast Thailand

From 110 saliva samples, 65 (59.1\%), 72 (65.5\%) and 57 (51.8\%) were positive according to semi-nested PCR, realtime PCR and IFA, respectively. Similarly, 50 (45.5\%), 80 (72.7\%) and 59 (53.6\%) of stool samples were positive according to semi-nested PCR, real-time PCR and IFA, respectively. Seventy-one (64.5\%) stool and 70 (63.6\%) saliva samples were positive for $H$. pylori according to at least two of the methods used (Additional file 1: Table S1). H. pylori was detected from both saliva and stool samples in 47 (42.72\%) persons (i.e. 94 true-positive samples from these individuals). From among these 141 samples, 70 were randomly selected for vacA PCR/sequencing, but sequencing was only successful for 43 samples. Twenty-four of the sequenced samples were matched stool and saliva from each of 12 individuals: saliva samples only were sequenced from a further nine individuals, and stool samples only from a further ten individuals (Fig. 1). There were 98/110 (89.1\%) saliva and 91/110 (82.7\%) stool samples that were positive to at least one method. In spiked stool samples, the limit of detection (LOD) of semi-nested PCR targeting vacA was $10^{1}$ CFUs/0.1 g. The limit for real-time PCR targeting $16 \mathrm{~S}$ rRNA gene was also $10^{1} \mathrm{CFUs} / 0.1 \mathrm{~g}$, and for IFA the limit was $10^{2}$ CFUs/0.1 g (Fig. 2).

\section{Risk factors for $H$. pylori colonization in oral cavity and intestinal tract}

The risk factors for $H$. pylori colonization were investigated. Most infected participants were female, aged more 


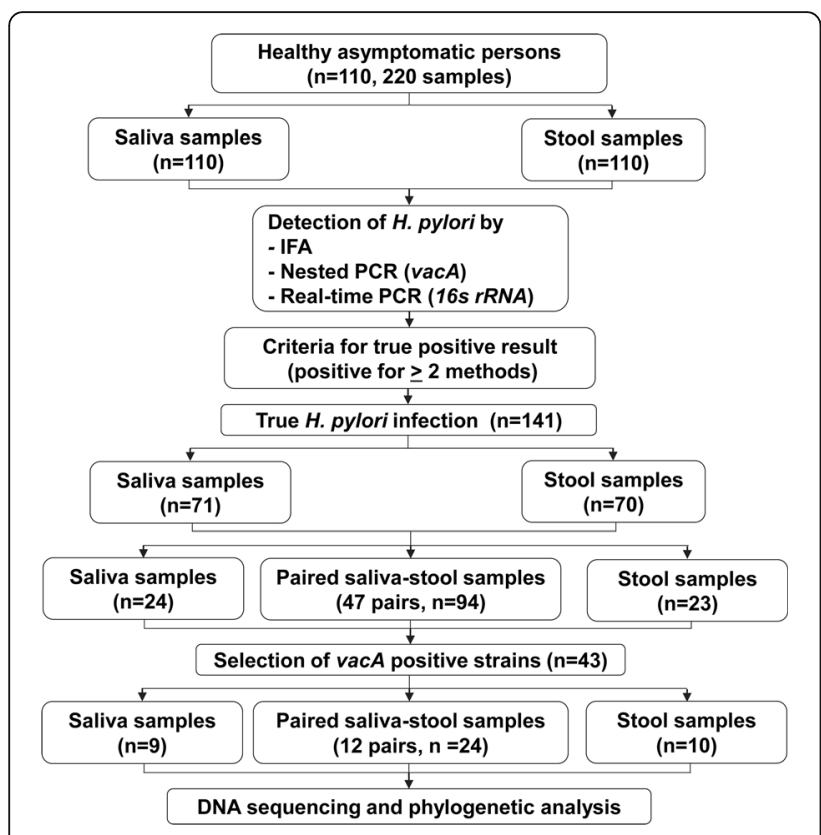

Fig. 1 Study population and classification criteria of the tested samples

than 40 and worked in agriculture. There was no significant association between $H$. pylori colonization and risk factors including age, gender, occupation and frequency of brushing teeth (Table 2).

\section{Genetic diversity and association of $H$. pylori in saliva and stool samples}

Phylogenetic analysis of $H$. pylori placed sequences of the vacA gene into two main groups (Fig. 3). Cluster 1 is a mixed group comprising 8 strains from stool samples, 20 strains from saliva samples and 8 reference strains from different countries. Cluster 2 comprised 14 strains from stool samples and only a single strain from saliva and this proportion is significantly different $(p=0.001)$. Based on the 12 subjects from which both saliva and stool samples were sequenced, 7 pairs were in separate clusters (cluster 1 saliva and cluster 2 for stool samples).

\section{Discussion}

H. pylori is a fastidious bacterium that can convert into a viable but non-culturable state, leading to difficulty in identifying its presence [25]. On the other hand, the detection of $H$. pylori using antigen or PCR-based methods directly from clinical samples might be non-specific due to cross reactivity. These limitations could have affected estimates of the prevalence of $H$. pylori infection in previous studies. Detection of several target genes together, such as ure A, glmM, ureC, $16 \mathrm{~S}$ rRNA, 23S rRNA, hsp60, and $v a c \mathrm{~A}$, helps to reduce the number of false positive results, especially for samples other than gastric biopsy specimens [25]. Therefore, we used stringent criteria for detection of $H$. pylori directly from saliva and stool samples based on in-house IFA and molecular methods including semi-nested PCR (vacA) and SYBR-green real-time PCR (16S rRNA), the latter modified from [24]. We found that the prevalences of $H$. pylori in asymptomatic healthy persons are comparable between saliva and stool samples in our region at $64 \%$. This number is similar to the prevalences of $H$. pylori, detected based on 16S rRNA, in asymptomatic subjects in India $(66.7 \%$ in saliva and $77.3 \%$ in stool samples) [10]. However, such estimates can vary depending on the region of study and method of detection. For example, one study in India, using PCR targeting hsp60, found prevalences of $45.7 \%$ in saliva and $42.8 \%$ in stools [11]. A study in Nigeria, using PCR targeting $g \operatorname{lm} \mathrm{M}$, estimated a prevalence of only $20.6 \%$ [14]. A previous study from Thailand, using detection of $16 \mathrm{~S}$ rRNA in stool samples, estimated a prevalence of $38.5 \%$ [13]. We required positive results from at least two testing methods before accepting that a sample was positive. If we had accepted only a single positive test result, our estimate of prevalence would have been even higher, around $80 \%$. Differences in prevalence estimates between the previous study and ours might reflect a higher current prevalence of $H$. pylori in healthy persons. The previous study in India [11] found older age and occupation as cattlemen and agriculturists to be associated with $H$. pylori infection [26]. Factors contributing to the high prevalence we found in our study, such as age and occupation, should be considered.

So far, vacA has been detected in all studied H. pylori strains [27-30] and hence has been used as a specific, conserved target for detection of this species. Our study showed that combined semi-nested PCR targeting vacA and real-time PCR targeting the 16S rRNA gene increased the detection rate, as one target only may occasionally fail to amplify. The IFA technique can detect viable cells of $H$. pylori using specific antibodies against bacterial protein [31]. The LOD of this method in spiked stool samples was $10^{2}$ cells $/ 0.1 \mathrm{~g}$. Both of the PCR-based methods used in our study had LODs at $10^{1}$ cells/ $/ 0.1 \mathrm{~g}$ in spiked stool samples. These values are similar to those obtained in a previous study from our group that showed LODs at $10^{1}$ cells $/ \mathrm{ml}$ in pure culture and spiked saliva samples [32].

Risk factors for H. pylori infection remain unclear. Socioeconomic conditions such as young age, low income and crowded dwellings have been reported as associated with $H$. pylori infection [33]. We found no significant association between $H$. pylori colonization and age, gender, occupation or frequency of brushing teeth. Reported prevalences of $H$. pylori infection were as low as $<5 \%$ in saliva and stool samples of children aged $<5$ years, but had increased to approximately $58.3 \%$ in the age group of 11-16 years and remained static in the range of 56$63 \%$ up to the age of 60 years [11]. Perhaps this explains 
a
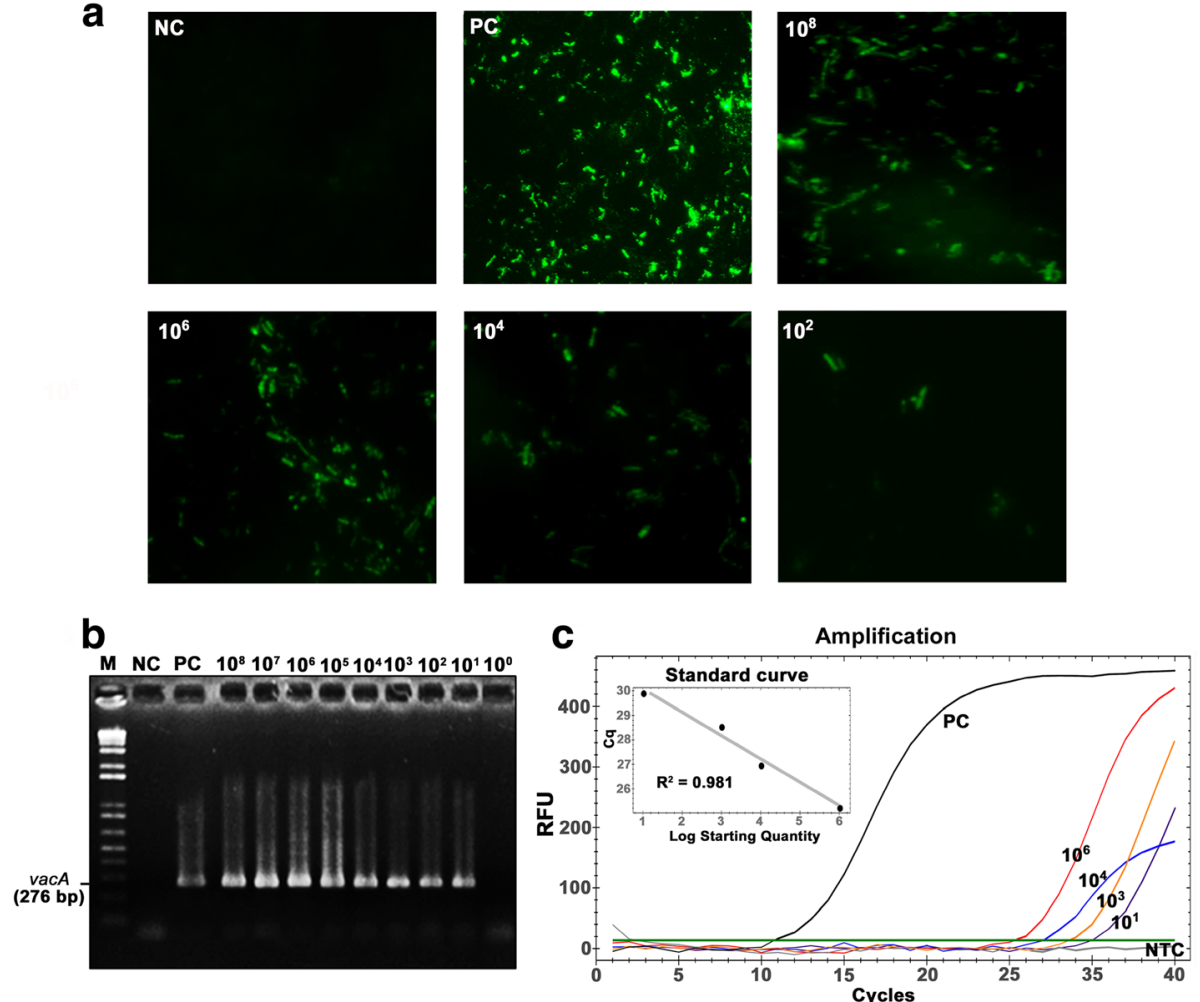

Fig. 2 Detection of H. pylori directly from stool samples using IFA, semi-nested PCR targeting vacA and real-time PCR targeting 16S rRNA. (A) Fluorescent photomicrograph of H. pylori in various concentrations (CFUs/0.1 g), NC and PC refers to negative (sterile Brucella broth) and positive control (H. pylori DMST 20165 in Brucella broth), respectively. (B) Semi-nested PCR targeting vacA in spiked stool samples. Lane M, 1 kb DNA ladder; Lane 1, negative control (PCR reagent without DNA); Lane 2, positive control (DNA sample from H. pylori DMST20165); Lanes 3-11, stool samples spiked with various numbers of $H$. pylori cells $\left(10^{8}-10^{\circ} \mathrm{CFUs} / 0.1 \mathrm{~g}\right)$. (C) Amplification curve of SYBR green real-time PCR targeting $16 \mathrm{~S}$ rRNA in spiked stool samples. Black line, positive control (DNA sample from H. pylori DMST20165); Red line, $10^{6}$; orange line, $10^{4}$; blue line, $10^{3}$; purple line, $10^{1} \mathrm{CFUs} / 0.1 \mathrm{~g}$; grey line, Non-template control (PCR reagent without DNA)

Table 2 Risk factors for colonization of $H$. pylori in saliva and stool samples of asymptomatic patients

\begin{tabular}{|c|c|c|c|c|}
\hline Risk factors for $\mathrm{H}$. pylori colonization & \multicolumn{2}{|c|}{ H. pylori detection* $(n, \%)$} & \multirow[t]{2}{*}{ Crude odds ratios (95\% Cl) } & \multirow[t]{2}{*}{ Adjusted odds ratios*** $(95 \% \mathrm{Cl})$} \\
\hline Saliva samples & Positive $(n=71)$ & Negative $(n=12)$ & & \\
\hline$\geq 40$ years & $60(84.5 \%)$ & $11(91.7 \%)$ & $0.50(0.06-4.24)$ & $0.45(0.05-3.85$ \\
\hline Female gender & $41(57.7 \%)$ & $8(66.7 \%)$ & $0.68(0.19-2.48)$ & $0.91(0.27-3.10$ \\
\hline Agriculturist & $62(87.3 \%)$ & $11(91.7 \%)$ & $0.63(0.07-5.45)$ & $0.59(0.07-5.25)$ \\
\hline Teeth brushing $\geq 2$-time a day** & $69(97.2 \%)$ & $11(91.7 \%)$ & $3.13(0.26-37.58)$ & $4.26(0.29-63.04)$ \\
\hline Stool samples & Positive $(n=70)$ & Negative $(n=19)$ & & \\
\hline$\geq 40$ years & $61(87.1 \%)$ & $16(84.2 \%)$ & $0.80(0.16-4.04)$ & $0.66(0.13-3.34)$ \\
\hline Female gender & $40(56.3 \%)$ & $14(73.7 \%)$ & $0.48(0.15-1.47)$ & $0.70(0.25-1.96)$ \\
\hline Agriculturist & $64(91.4 \%)$ & $15(78.9 \%)$ & $2.00(0.45-8.88)$ & $3.27(0.77-13.97)$ \\
\hline Teeth brushing $\geq 2$-time a day** & 68 (97.1\%) & 18 (94.7\%) & $1.76(0.15-20.51)$ & $2.62(0.20-34.82)$ \\
\hline
\end{tabular}

*Only true positives (positive according to at least 2 methods) and true negatives (negative by all methods) were included in the analysis

**Teeth brushing once a day was used as reference

***Multivariate analysis was adjusted for age and gender 


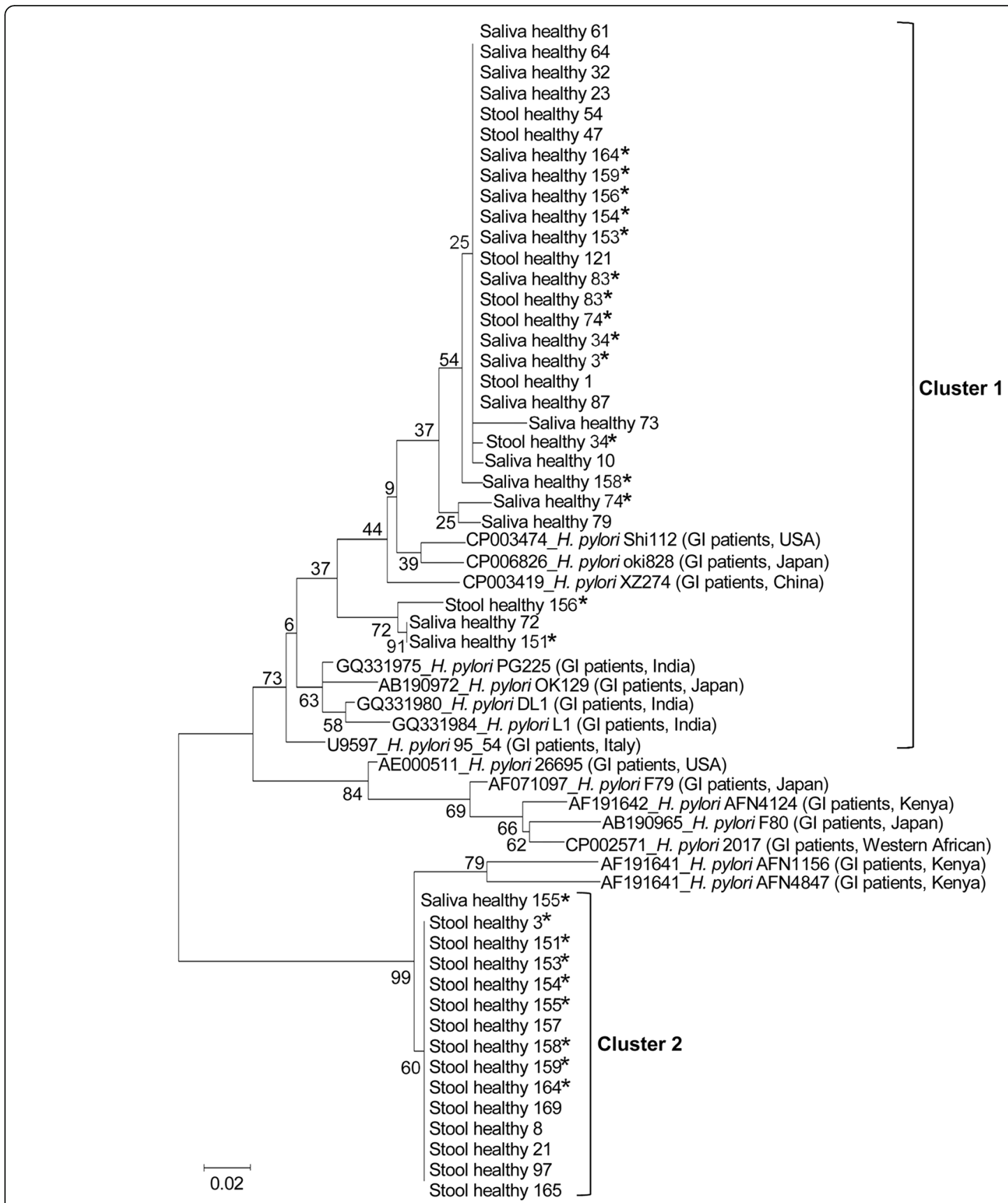

Fig. 3 Maximum Likelihood tree of 276-bp vacA gene H. pylori isolated from saliva and stool samples of asymptomatic individuals from Northeastern Thailand. An asterisk indicates the 12 subjects from which the vacA gene in both saliva and stool samples were sequenced. In seven out of 12 pairs (Healthy 3, 151,153, 154, 158, 159 and 164), sequences of $H$. pylori detected from saliva samples were in a separate cluster to those from stool samples

why we failed to demonstrate an association between age and infection: most of our participants were adults. Some previous studies have reported significantly higher prevalences of $H$. pylori in males than in females [34, 35]. Others have found no association with gender $[11,15]$, a result that agrees with our findings. Higher prevalences have been reported previously in cattlemen and agriculturists, suggesting possible zoonotic transmission [26]. Living in rural areas and exposure to poor hygiene conditions was speculated as a major risk factor [36, 37]. However, despite the fact that the subjects in our study lived in rural areas and most were agriculturists (89.1\%), no significant association between occupation and the presence of $H$. pylori in saliva and stool samples was found. Previously, poor 
oral health and oral diseases have been reported as associated with the infection of $H$. pylori in the oral cavity [38]. Others have found no correlation between the presence of H. pylori in the oral cavity and oral hygiene habits (e.g. teeth brushing and the use of mouthwash) [39]. We found no association between frequency of brushing and $H$. pylori colonization.

Momtaz et al. [16] genotyped $v a c \mathrm{~A}$ and $c a g \mathrm{~A}$ from saliva, gastric biopsies and stool samples and concluded that $H$. pylori was transmitted via the fecal-oral route. We investigated the phylogeny of $H$. pylori based on sequences within the conserved region of the vacA gene from saliva and stool samples. We found that $7 / 12$ participants (for whom sequences were obtained both from saliva and stool samples) contained $H$. pylori strains associated with tissue location, i.e. oral strains largely belonged to cluster 1 and stool strains to cluster 2 in the phylogenetic tree. This suggests that particular $H$. pylori strains might have preferred tissue sites for colonization or differential ability to survive within the gastrointestinal tract such as the acidic site inside the stomach. Vacuolating cytotoxin A, encoded by $v a c \mathrm{~A}$, is involved in several processes of pathogenesis including pore formation of the infected cells [40]. A pHdependent structural change in vacuolating cytotoxin A has been reported [41]. Genetic variants of vacA might exhibit differences in toxin activity in the acidic environment of the stomach, influencing bacterial survival. Further study of this possibility is needed.

Previous studies could not identify distinct genetic variants that might be associated with particular sites in the host. This might have been due to their use of methods with low discriminatory power $[16,17]$ or be a consequence of small sample size [18]. In our study, the majority (7/12) of individuals for which both stool and saliva samples were sequenced contained $H$. pylori strains associated with tissue location, i.e. oral strains largely belonged to cluster 1 and stool strains to cluster 2 in the phylogenetic tree. Based on our observations under the microscope, the sizes of the bacterial cells and colonies are similar between strains isolated from the two sites. Because H. pylori is a fastidious organism and difficult to isolate on artificial media [42], we did not perform the phenotypic assay. Among the five individuals for whom $H$. pylori oral (saliva) and intestinal (stool) pairs of sequences fell in the same cluster, four were in cluster 1 . Possibly cluster 1 strains are better able to survive in the stomach and/or intestinal tract. Although we found frequent differences between $v a c \mathrm{~A}$ genotypes in the oral cavity and intestinal tract samples from the same individual, the number of these paired samples is still low. Additional study with an increased number of paired samples could overcome this limitation. Further investigation of genetic and strain diversity in $\mathrm{H}$. pylori and their ability to survive within different host conditions, such as the acidic conditions in the stomach, is clearly warranted.

\section{Conclusion}

In summary, we found that the prevalence of $H$. pylori in the asymptomatic, apparently healthy population is around $64 \%$ in both saliva and stool samples. This high prevalence increases the risk of development of associated diseases. Although the fecal-oral route is the major mode of transmission of $\mathrm{H}$. pylori, genotypes of the vacA gene often differed between oral cavity and intestinal tract samples. Tissue-specific subtypes of $H$. pylori subtypes might be associated with different virulence properties, a phenomenon requiring further investigation.

\section{Additional file}

Additional file 1: Table S1. Detection of $H$. pylori true positive result in saliva and stool samples. (DOCX $12 \mathrm{~kb}$ )

\section{Abbreviations}

CFU: Colony forming unit; IFA: Indirect immunofluorescence assay; LODs: Limit of detections; vacA: Vacuolating cytotoxin A

\section{Acknowledgements}

This study was supported by Faculty of Medicine, Khon Kaen University. We would like to acknowledge Prof. David Blair for editing the MS via Publication Clinic KKU

\section{Funding}

This study was financially supported for the study design and sample collection by general supportive research grant, Khon Kaen University, Thailand 2016. Kiatichai Faksri is supported by Thailand Research Fund for data analysis and written manuscript (MRG 5980002). Bancrob Sripa is the Thailand Research Fund Senior Research Scholar (RTA 5680006). Phattharaphon Wongphutorn is supported by the scholarship from Liver Fluke and Cholangiocarcinoma Research Center (LFCRC).

\section{Availability of data and materials}

The datasets used and/or analyzed during the current study available from the corresponding author on reasonable request.

\section{Authors' contributions}

CC and KF designed the study, PW and BS collected the specimens, PW implemented the experiments following the study design, KF and CC administered the experiments, PW and KF analyzed the data, KF interpreted the data, KF wrote the manuscript, KF edit the manuscript and conducted the publishing process, BS gave the technical support and conceptual advice, WN facilitated the primer design and gave the conceptual advice. All authors have read and approved of the final manuscript.

\section{Ethics approval and consent to participate}

Written ethical consents were received from participants. The study was approved by Institutional Human Ethics Committee of Khon Kaen University (HE571489).

\section{Consent for publication}

Not applicable.

\section{Competing interests}

The authors declare that they have no competing interests.

\section{Publisher's Note}

Springer Nature remains neutral with regard to jurisdictional claims in published maps and institutional affiliations. 


\section{Author details}

'Department of Microbiology, Faculty of Medicine, Khon Kaen University, Khon Kaen 40002, Thailand. ${ }^{2}$ Liver Fluke and Cholangiocarcinoma Research Center, Khon Kaen University, Khon Kaen 40002, Thailand. ${ }^{3}$ Department of Pathology, Faculty of Medicine, Khon Kaen University, Khon Kaen 40002, Thailand. ${ }^{4}$ Research and Diagnostic Center for Emerging Infectious Diseases (RCEID), Khon Kaen University, Khon Kaen 40002, Thailand.

Received: 27 April 2017 Accepted: 21 January 2018

Published online: 30 January 2018

\section{References}

1. Kusters JG, van Vliet AH, Kuipers EJ. Pathogenesis of Helicobacter pylori infection. Clin Microbiol Rev. 2006;19(3):449-90.

2. Wu MS, Lee WJ, Wang HH, Huang SP, Lin JT. A case-control study of association of Helicobacter pylori infection with morbid obesity in Taiwan. Arch Intern Med. 2005;165(13):1552-5.

3. Pounder RE, Ng D. The prevalence of Helicobacter pylori infection in different countries. Aliment Pharmacol Ther. 1995;9(Suppl 2):33-9.

4. Khatoon J, Rai RP, Prasad KN. Role of Helicobacter pylori in gastric cancer: updates. World J Gastrointest Oncol. 2016;8(2):147-58.

5. Leelawat K, Suksumek N, Leelawat S, Lek-Uthai U. Detection of VacA gene specific for Helicobactor pylori in hepatocellular carcinoma and cholangiocarcinoma specimens of Thai patients. Southeast Asian J Trop Med Public Health. 2007;38(5):881-5.

6. Tiwari SK, Khan AA, Ibrahim M, Habeeb MA, Habibullah CM. Helicobacter pylori and other Helicobacter species DNA in human bile samples from patients with various hepato-biliary diseases. World Journal of Gastroenterology : WJG. 2006;12(14):2181-6.

7. Boonyanugomol W, Chomvarin C, Hahnvajanawong C, Sripa B, KaparakisLiaskos M, Ferrero RL. Helicobacter pylori cag pathogenicity island (cagPAl) involved in bacterial internalization and IL-8 induced responses via NOD1and MyD88-dependent mechanisms in human biliary epithelial cells. PLoS One. 2013;8(10):e77358.

8. Sripa B, Kaewkes S, Sithithaworn P, Mairiang E, Laha T, Smout M, Pairojkul C, Bhudhisawasdi V, Tesana S, Thinkamrop B, et al. Liver fluke induces cholangiocarcinoma. PLoS Med. 2007:4(7):e201.

9. Sriamporn S, Pisani P, Pipitgool V, Suwanrungruang K, Kamsa-ard S, Parkin DM. Prevalence of Opisthorchis viverrini infection and incidence of cholangiocarcinoma in Khon Kaen, Northeast Thailand. Tropical Med Int Health. 2004;9(5):588-94.

10. Mahajan D, Jain A, Singh V, Jain AK, Rao GR, Nath G. Detection of Helicobacter pylori using nested polymerase chain reaction in gastric biopsy samples. Indian journal of clinical biochemistry : IJCB. 2008;23(3):243-5.

11. Mishra S, Singh V, Rao GR, Dixit VK, Gulati AK, Nath G. Prevalence of Helicobacter pylori in asymptomatic subjects-a nested PCR based study. Infect Genet Evol. 2008;8(6):815-9.

12. Ding Z, Zhao S, Gong S, Li Z, Mao M, Xu X, Zhou L. Prevalence and risk factors of Helicobacter pylori infection in asymptomatic Chinese children: a prospective, cross-sectional, population-based study. Aliment Pharmacol Ther. 2015;42(8):1019-26.

13. Hirai I, Sasaki T, Kimoto A, Yamamoto Y, Azuma T, Mahachai V, Hansomburana P, Lertkupinit C, Luangjaru S, Noophan P, et al. Infection of less virulent Helicobacter pylori strains in asymptomatic healthy individuals in Thailand as a potential contributing factor to the Asian enigma. Microbes Infect. 2010;12(3):227-30.

14. Smith SI, Fowora MA, Lesi OA, Agbebaku E, Odeigah P, Abdulkareem FB, Onyekwere CA, Agomo CA, Contreras M. Application of stool-PCR for the diagnosis of Helicobacter pylori from stool in Nigeria- a pilot study. SpringerPlus. 2012;1 (1):78.

15. Ghosh P, Bodhankar SL. Association of smoking, alcohol and NSAIDs use with expression of cagA and cagT genes of Helicobacter pylori in salivary samples of asymptomatic subjects. Asian Pacific Journal of Tropical Biomedicine. 2012;2(6):479-84.

16. Momtaz H, Souod N, Dabiri H, Sarshar M. Study of Helicobacter pylori genotype status in saliva, dental plaques, stool and gastric biopsy samples. World J Gastroenterol. 2012;18(17):2105-11.

17. Souto R, Colombo AP. Detection of Helicobacter pylori by polymerase chain reaction in the subgingival biofilm and saliva of non-dyspeptic periodontal patients. J Periodontol. 2008;79(1):97-103.
18. Wang J, Chi DS, Laffan JJ, Li C, Ferguson DA Jr, Litchfield P, Thomas E. Comparison of cytotoxin genotypes of Helicobacter pylori in stomach and saliva. Dig Dis Sci. 2002;47(8):1850-6.

19. Deenonpoe R, Mairiang E, Mairiang P, Pairojkul C, Chamgramol Y, Rinaldi G, Loukas A, Brindley PJ, Sripa B. Elevated prevalence of helicobacter species and virulence factors in opisthorchiasis and associated hepatobiliary disease. Sci Rep. 2017;7:42744.

20. Silva DG, Stevens RH, Macedo JM, Albano RM, Falabella ME, Veerman EC, Tinoco EM. Detection of cytotoxin genotypes of Helicobacter pylori in stomach, saliva and dental plaque. Arch Oral Biol. 2009;54(7):684-8.

21. Tirapattanun A, Namwat W, Kanthawong S, Wongboot W, Wongwajana S, Wongphutorn P, Chomvarin C. Detection of Heicobacter pylori and virulence-associated genes in saliva samples of asymptomatic person in northeast of Thailand. The Southeast Asian journal of tropical medicine and public health. 2016;47(6) in press.

22. Horemans T, Deschacht M, Clais S, Van Camp J, de Rijk P, Holvoet J, Van Assche T, Maes L, Cos P. An alternative, sensitive method to detect Helicobacter pylori DNA in feces. Helicobacter. 2011;16(2):113-8.

23. Kumar S, Stecher G, Tamura K. MEGA7: molecular evolutionary genetics analysis version 7.0 for bigger datasets. Mol Biol Evol. 2016;33(7):1870-4.

24. Ottiwet O, Chomvarin C, Chaicumpar K, Namwat W, Mairiang P. Nested polymerase chain reaction for detection of Helicobacter pylori in gastric biopsy specimens. Southeast Asian J Trop Med Public Health. 2010;41 (6):1423-31.

25. Wang YK, Kuo FC, Liu CJ, Wu MC, Shih HY, Wang SS, Wu JY, Kuo CH, Huang YK, Wu DC. Diagnosis of Helicobacter pylori infection: current options and developments. World J Gastroenterol. 2015;21(40):11221-35.

26. Goodman KJ, Correa P, Tengana Aux HJ, Ramirez H, DeLany JP, Guerrero Pepinosa O, Lopez Quinones M, Collazos Parra T. Helicobacter pylori infection in the Colombian Andes: a population-based study of transmission pathways. Am J Epidemiol. 1996;144(3):290-9.

27. Avenaud P, Marais A, Monteiro L, Le Bail B, Bioulac Sage P, Balabaud C, Megraud F. Detection of Helicobacter species in the liver of patients with and without primary liver carcinoma. Cancer. 2000;89(7):1431-9.

28. Huang Y, Fan XG, Wang ZM, Zhou JH, Tian XF, Li N. Identification of helicobacter species in human liver samples from patients with primary hepatocellular carcinoma. Am J Clin Pathol. 2004;57(12):1273-7.

29. Ito K, Nakamura M, Toda G, Negishi M, Torii A, Ohno T. Potential role of Helicobacter pylori in hepatocarcinogenesis. Int J Mol Med. 2004;13(2):221-7.

30. Yan J, Mao YF. Construction of a prokaryotic expression system of vacA gene and detection of vacA gene, VacA protein in Helicobacter pylori isolates and ant-VacA antibody in patients' sera. World J Gastroenterol. 2004;10(7):985-90.

31. lankov ID, Penheiter AR, Carlson SK, Galanis E. Development of monoclonal antibody-based immunoassays for detection of Helicobacter pylori neutrophil-activating protein. J Immunol Methods. 2012;384(1-2):1-9.

32. Tirapattanun A: Development of detection methods for Vibrio cholerae and Helicobacter pylori in environmental and clinical specimens [M.Sc. Thesis in Medical Microbiology] Khon Kaen: The Graduate School, Khon Kaen University 2015.

33. Hasosah M, Satti M, Shehzad A, Alsahafi A, Sukkar G, Alzaben A, Sunaid A, Ahmed A, AlThubiti S, Mufti A, et al. Prevalence and risk factors of Helicobacter pylori infection in Saudi children: a three-year prospective controlled study. Helicobacter. 2015;20(1):56-63.

34. Zheng Y, Liu M, Shu H, Chen Z, Liu G, Zhang Y. Relationship between oral problems and Helicobacter pylori infection. Arch Oral Biol. 2014;59(9):938-43.

35. de Martel C, Parsonnet J. Helicobacter pylori infection and gender: a metaanalysis of population-based prevalence surveys. Dig Dis Sci. 2006;51(12): 2292-301.

36. Brown LM, Thomas TL, Ma JL, Chang YS, You WC, Liu WD, Zhang L, Pee D, Gail MH. Helicobacter pylori infection in rural China: demographic, lifestyle and environmental factors. Int J Epidemiol. 2002;31(3):638-45.

37. Cheng H, Hu F, Zhang L, Yang G, Ma J, Hu J, Wang W, Gao W, Dong X. Prevalence of Helicobacter pylori infection and identification of risk factors in rural and urban Beijing, China. Helicobacter. 2009;14(2):128-33.

38. Yu M, Zhang XY, Yu Q. Detection of oral Helicobacter pylori infection using saliva test cassette. Pak J Med Sci. 2015;31(5):1192-6.

39. Fernandez-Tilapa G, Axinecuilteco-Hilera J, Giono-Cerezo S, Martinez-Carrillo DN, Illades-Aguiar B, Roman-Roman A. vacA genotypes in oral cavity and Helicobacter pylori seropositivity among adults without dyspepsia. Med Oral Patol Oral Cir Bucal. 2011;16(2):175-80.

40. Palframan SL, Kwok T, Gabriel K. Vacuolating cytotoxin a (VacA), a key toxin for Helicobacter pylori pathogenesis. Front Cell Infect Microbiol. 2012;2:92. 
41. MS MC, Schraw W, Ricci V, Boquet P, Cover TL. Acid activation of Helicobacter pylori vacuolating cytotoxin (VacA) results in toxin internalization by eukaryotic cells. Mol Microbiol. 2000;37(2):433-42.

42. Thomas JE, Gibson GR, Darboe MK, Dale A, Weaver LT. Isolation of Helicobacter pylori from human faeces. Lancet. 1992;340(8829):1194-5.

43. Rinttila T, Kassinen A, Malinen E, Krogius L, Palva A. Development of an extensive set of $165 \mathrm{rDNA}$-targeted primers for quantification of pathogenic and indigenous bacteria in faecal samples by real-time PCR. J Appl Microbiol. 2004;97(6):1166-77.

Submit your next manuscript to BioMed Central and we will help you at every step:

- We accept pre-submission inquiries

- Our selector tool helps you to find the most relevant journal

- We provide round the clock customer support

- Convenient online submission

- Thorough peer review

- Inclusion in PubMed and all major indexing services

- Maximum visibility for your research

Submit your manuscript at www.biomedcentral.com/submit
Biomed Central 